\title{
Reconsidering Internet Gaming Disorder During the COVID-19 Pandemic
}

\author{
Elyse Blake ${ }^{1} \cdot$ Daniel Sauermilch $^{2}$ (D) \\ Received: 4 September 2020 / Revised: 12 October 2020 / Accepted: 25 November 2020 / Published online: 15 January 2021 \\ (C) The Author(s), under exclusive licence to Springer Nature Switzerland AG part of Springer Nature 2021
}

The discourse surrounding the classification of gaming disorders has teemed with debate in recent years (American Psychiatric Association 2013b; Kuss et al. 2017; World Health Organization 2015). In 2013, a provisional diagnosis of Internet gaming disorder (IGD) was tentatively included in the 5th edition of the Diagnostic and Statistical Manual of Mental Disorders (DSM-5) contingent on further evidence to warrant IGD's existence as an independent disorder altogether (APA 2013b; WHO 2015). In spite of calls to delay the inclusion of a similar diagnosis in the 11 th edition of the International Classification of Diseases, the World Health Organization voted to formalize the diagnosis of gaming disorder in 2019 (van Rooij et al. 2018; WHO 2019). While debate over the validity of IGD and its diagnostic criteria continues, concurrent research on the demographic characteristics of gamers in the USA has found that $10 \%$ of gamers nationwide - over 18 years of age - identify as a sexual or gender minority (Nielsen Community 2020).

Online gaming has greatly evolved in recent years (Johnson 2019). Contextualized by the monetization of certain gaming platforms, research has acknowledged the importance of gaming for ethnic and racial minority gamers as well as gamers living with chronic conditions and physical disabilities (Gray 2017; Johnson 2019; Leonard 2019). Besides gaming as a potential source of income, sexual and gender minority populations' engagement with gaming is not new. In fact, the inclusion of queer characters and storylines in popular games as of late may signal an already extant subpopulation of gamers living with marginalized identities rather than a shift in the population (Parker 2016). Limited research has also indicated that gaming occupies a unique role among

Daniel Sauermilch

dbs2179@tc.columbia.edu

1 Gordon F. Derner School of Psychology, Adelphi University, New York, NY, USA

2 Teachers College, Columbia University, 525 W 120th Street, New York City, NY 10027, USA
LGBTQ+ populations in respect to sexual and gender identity formation and expression. Role play games, for example, may provide sexual and gender minority gamers the freedom of gender expression otherwise not afforded to them in-person (Griffiths et al. 2016). Further research has also indicated that such forms of gaming may provide an entry point for gamers to safely explore their sexual identity in relative anonymity (Nielsen 2015). As such, the recently released data on LGBTQ+ gamers may serve to further justify future research on the psychosocial benefits of gaming for sexual and gender minority populations in the USA (Nielsen Community 2020).

The Coronavirus Disease 2019 (COVID-19) pandemiccaused by the severe acute respiratory syndrome coronavirus 2 (SARS-Cov-2) - has seen a marked increase in the consumption of video game products across the USA possibly due to the enforcement of the Centers for Disease Control and Prevention's social distancing and self-isolation guidelines (CDC 2020; The NPD Group 2020). Further, while sexual and gender minority populations in the USA regularly face unique stressors, such as a lack of social support or discrimination on the basis of sexual or gender identity, emerging research has also indicated that such populations are at unique risk of COVID-19 infection due to a confluence of factors (Meyer 2003; Phillips et al. 2020). These factors include a high likelihood to work in essential industries, inadequate health insurance coverage, job insecurity, and other variables, which increase this aforementioned risk of infection (Human Rights Campaign Foundation 2020). In fact, burgeoning research on sexual minority men in the USA found that over $19 \%$ of the study cohort reported job loss due to the pandemic alone, testifying to the socioeconomic vulnerability of such minority groups (Sanchez et al. 2020).

While research has been limited, gaming may present as a common form of emotion-focused coping for sexual and gender minorities broadly (Kuo et al. 2016; Lazarus 2006; Meyer 2003). Further, gaming among LGBTQ+ populations may become increasingly popular as the pandemic persists - as recent research has shown (Fish et al. 2020). Considering this limited, but emerging data on LGBTQ+ gamers in the USA, 
as well as the distinct social context of the COVID-19 pandemic for such populations, it is imperative to discuss the implications of both sexual and gender identity as well as the current public health crisis on the diagnostic criteria of future iterations of gaming disorder classifications.

Although gamers nationwide are by average $35-44$ years of age, most diagnoses of IGD occur in adolescents (ESA 2020; Wu et al. 2018). This statistic may be evidence of the often-overlooked role of parents in the IGD diagnostic process, the so-called first line in perceiving problematic Internet and gaming use in their children (Bonnaire et al. 2019; Gentile et al. 2017; Schneider et al. 2017). Negative parental attitudes toward gaming and lower family functioning have been found to be reliable predictors of IGD among adolescents, though more research on the role parents play in the diagnosis of IGD is needed (Bonnaire and Phan 2017). The COVID-19 pandemic places parents in a unique position in respect to IGD. Despite the resumption of in-person learning in some states, others are expected to continue online learning until the approval of a COVID-19 vaccine (Sheikh et al. 2020). As such, adolescent populations in the USA may naturally increase their Internet consumption as a necessity while sexual and gender minority youth, in particular, may engage in gaming at typical or increased rates as a function of gender expression, identity formation, and emotion-focused coping (Fish et al. 2020; Griffiths et al. 2016; Guessoum et al. 2020).

Since parents have become de facto educators in lieu of formal in-person instruction, they may also become preoccupied with the perceived increase in gaming behaviors of their children and consequently seek mental healthcare services to assuage their concern (Bonnaire and Phan 2017). At the same time, research has shown that the risk factors for IGD, based on the DSM-5 criteria, have been unable to distinguish problem gamers from recreational gamers, shedding light on the complex and nuanced role that parents may play in the diagnostic process (Jory et al. 2017). Therefore, the USA may see a disproportionate increase in treatment seeking for symptoms consistent with IGD - not from those exhibiting the symptoms, but from parents who are distressed by their children's gaming behavior.

This narrative of how mental healthcare practitioners may see a higher prevalence of IGD related symptoms is speculativeand some may also question the detrimental effect of an IGD diagnosis in such cases altogether. However, limited research has indicated that gaming, notwithstanding the diagnosis of IGD, is met with immense social stigma (Peter et al. 2019). While an IGD diagnosis would not be the only diagnosis to be met with such stigma, IGD is unique due to its provisional inclusion in the DSM-5 contingent on further research (Parcesepe and Cabassa 2013). As studies on the expression of IGD symptoms continue during the current pandemic, researchers would be remiss not to contextualize the detrimental impact such a diagnosis may produce for vulnerable sexual and gender minority populations in the USA. Moreover, while the diagnosis of other disorders (e.g., substance use disorders) may also be met with the aforementioned social stigma, a formal diagnosis of IGD fails to account for the benefits of gaming (which substance use does not impart) for LGBTQ+ populations notwithstanding (Kowert et al. 2014).

Furthermore, while the treatment of IGD symptoms has pulled from multiple theoretical approaches and types (including cognitive behavioral therapy and psychopharmacological treatments), the treatment of substance use disorders has also served as a template for IGD interventions (Zajac et al. 2017). In fact, as research has touted the prescription of bupropion for the treatment of IGD symptoms, this pharmacological regimen is also commonly prescribed for the treatment of nicotine addictionwhich may be emblematic of IGD's conception as similar to substance use disorders (Petry et al. 2018; Song et al. 2016). Additionally, research on policy-level interventions for IGD symptoms abroad has found that such structural efforts to mitigate problematic gaming use through prohibitive measures are similar to policies that aim to curb alcohol consumption (Király et al. 2018).

"Wilderness" therapies, commonly used in the treatment of substance use disorders, are also endorsed for the treatment of IGD symptoms (Bennett et al. 1998; Király et al. 2018). Such therapies consist of an abatement of the "substance" or a lengthy "detox" process via costly in-patient treatment programs and cognitive behavioral therapy (Király et al. 2018; Wang et al. 2019; Xiang et al. 2020). The goal of such treatment is for the gamer to disavow gaming and supplant gaming usage with supposed pro-social activities anchored in the non-virtual world (Peter et al. 2020). Yet, the logic behind such treatment for LGBTQ+ gamers is highly flawed as (1) gaming has been shown to be fundamentally interpersonal, and (2) IGD treatment fails to account for the potential benefits LGBTQ+ youth may reap from gaming in respect to gender and sexual expression during a particular formative developmental period (Institute of Medicine, Board on the Health of Select Populations, and Committee on Lesbian, G. B. T. H. I. R. G. O. 2011; Kowert et al. 2014). Further, while in-person interactions remain limited due to the pandemic, treatment that would posit such a change in activity from online to in-person is simply impractical.

Consequently, questions regarding how to proceed in the assessment of IGD and future classifications of gaming disorders in the age of COVID-19 demand our attention. Firstly, research ought to examine bias against technology and gaming in the field of mental healthcare. In a study, $61.5 \%$ of clinicians surveyed were concerned about the addictiveness of Internet gaming (Ferguson 2015). The abovementioned study suggests that such concern may be a function of warning bias toward new technology (e.g., Internet gaming), with clinician's age, gender, and negative attitude toward youth predicting negative attitudes toward gaming (Ferguson 2015). As this is the case, sexual and gender minority mental health consumers who engage in gaming as a means of sexual or gender identity expression may be treated 
by clinicians who could be averse to acknowledging the psychosocial benefits of gaming for these populations. Consequently, these attitudes toward technology may contribute to mental health inequities for LGBTQ+ populations in the USA.

Secondly, mental healthcare practitioners should also make efforts to understand sociocultural contexts (i.e., the COVID-19 pandemic and the role of gaming for LGBTQ+ gamers) as they may pertain to sexual and gender minority patients with symptoms of IGD. Such considerations may be achievable via the Cultural Formulation Interview included in the DSM-5 (APA 2013a). Although research has identified barriers to the use of this assessment tool (e.g., extra time needed for conducting the interview, patient discomfort with clinicians, and confusing syntax), it remains one of the few protocols that allows for the inclusion of culture-bound behavior in the diagnostic process (Aggarwal et al. 2013). An amendment to the interview protocol may also be warranted for LGBTQ+ adolescents in particular so as not to frame their gaming behavior as a problem before understanding how their use may, in fact, undergird their identity.

Such an amendment would take into account the age of the patient, especially if the patient is a minor, and the conditions under which they are speaking with a clinician. It would also be prudent for the Cultural Formulation Interview to remove reference to a "problem" in the introduction section of the protocol and use less charged language by asking about the reason for the patient's visit instead. Further, adopting the description used by the patient throughout the remainder of the interview - as opposed to first adopting said language in the "Cultural Definition of the Problem" section, as is currently instructed - would be an important change to make as well (APA 2013a).

As public health experts advise that COVID-19 may be further evidence of an onslaught of similar such coronaviruses to come, it is imperative that mental healthcare services consider the changing role of gaming among those at greatest risk for poor psychological and somatic health outcomes (Morens and Fauci 2020). Neglecting the psychosocial benefits of gaming for such populations during a critical phase of development would not only further contribute to the marginalization of sexual and gender minority populations broadly but would also undercut our own understanding of the mental health implications of gaming at large.

\section{Compliance with Ethical Standards}

Conflict of Interest The authors declare that they have no conflicts of interest.

\section{References}

Aggarwal, N. K., Nicasio, A. V., DeSilva, R., Boiler, M., \& LewisFernández, R. (2013). Barriers to implementing the DSM-5 cultural formulation interview: A qualitative study. Culture, Medicine and Psychiatry, 37(3), 505-533. https://doi.org/10.1007/s11013-0139325-z.

American Psychiatric Association (2013a). Cultural Formulation Interview.

American Psychiatric Association (2013b). Diagnostic and Statistical Manual of Mental Disorders-Fifth Edition.

Bennett, L. W., Cardone, S., \& Jarczyk, J. (1998). Effects of a therapeutic camping program on addiction recovery: The Algonquin haymarket relapse prevention program. Journal of Substance Abuse Treatment, 15(5), 469-474. https://doi.org/10.1016/S0740-5472(97)00222-5.

Bonnaire, C., \& Phan, O. (2017). Relationships between parental attitudes, family functioning and Internet gaming disorder in adolescents attending school. Psychiatry Research, 255, 104-110. https:// doi.org/10.1016/j.psychres.2017.05.030.

Bonnaire, C., Liddle, H. A., Har, A., Nielsen, P., \& Phan, O. (2019). Why and how to include parents in the treatment of adolescents presenting Internet gaming disorder? Journal of Behavioral Addictions, 8(2), 201-212. https://doi.org/10.1556/2006.8.2019.27.

Centers for Disease Control and Prevention (2020). Social distancing. https://www.cdc.gov/coronavirus/2019-ncov/prevent-getting-sick/ social-distancing.html. Accessed 2 Sept 2020.

Entertainment Software Association (2020). 2020 essential facts about the video game industry. https://www.theesa.com/esa-research/ 2020-essential-facts-about-the-video-game-industry/. Accessed 2 Sept 2020.

Ferguson, C. J. (2015). Clinicians' attitudes toward video games vary as a function of age, gender and negative beliefs about youth: A sociology of media research approach. Computers in Human Behavior, 52, 379-386. https://doi.org/10.1016/j.chb.2015.06.016.

Fish, J. N., McInroy, L. B., Paceley, M. S., Williams, N. D., Henderson, S., Levine, D. S., \& Edsall, R. N. (2020). "I'm kinda stuck at home with unsupportive parents right now": LGBTQ youths' experiences with COVID-19 and the importance of online support. Journal of Adolescent Health, 67(3), 450-452. https://doi.org/10.1016/j. jadohealth.2020.06.002.

Gentile, D. A., Bailey, K., Bavelier, D., Brockmyer, J. F., Cash, H., Coyne, S. M., Doan, A., Grant, D. S., Green, S. C., Griffiths, M., Markle, T., Petry, N. M., Prot, S., Rae, C. D., Rehbein, F., Rich, M., Sullivan, D., Woolley, E., \& Young, K. (2017). Internet gaming disorder in children and adolescents. Pediatrics, 140(Supplement 2), S81. https://doi.org/10.1542/peds.2016-1758H.

Gray, K. L. (2017). 'They're just too urban': Black gamers streaming on twitch. In J. Daniels, K. Gregory, \& T. McMillian Cottom (Eds.), Digital Sociologies. Bristol: Policy Press.

Griffiths, M., Arcelus, J., \& Bouman, W. (2016). Video gaming and gender dysphoria: Some case study evidence. Aloma: Revista de Psicologia, Ciències de l'Educació i de l'Esport, 34, 59-66.

Guessoum, S. B., Lachal, J., Radjack, R., Carretier, E., Minassian, S., Benoit, L., \& Moro, M. R. (2020). Adolescent psychiatric disorders during the COVID-19 pandemic and lockdown. Psychiatry Research, 291, 113264-113264. https://doi.org/10.1016/j. psychres.2020.113264.

Human Rights Campaign Foundation (2020). The lives and livelihoods of many in the LGBTQ community are at risk amidst COVID-19 crisis. Retrieved from https://assets2.hrc.org/files/assets/resources/ COVID19-IssueBrief-032020-FINAL.pdf? ga=2.104544256. 1051308685.1591915100-337428497.1591915100. Accessed 2 Sept 2020.

Institute of Medicine, Board on the Health of Select Populations, \& Committee on Lesbian, G. B. T. H. I. R. G. O. (2011). The Health of Lesbian, Gay, Bisexual, and Transgender People: Building a Foundation for Better Understanding: National Academies Press.

Johnson, M. R. (2019). Inclusion and exclusion in the digital economy: Disability and mental health as a live streamer on Twitch.tv. 
Information, Communication \& Society, 22(4), 506-520. https://doi. org/10.1080/1369118X.2018.1476575.

Jory, D., Filip, N., Lucien, R., Stéphane, R., Pierre, M., \& Joël, B. (2017). Established risk factors for addiction fail to discriminate between healthy gamers and gamers endorsing DSM-5 Internet gaming disorder. Journal of Behavioral Addictions, 6(4), 516-524. https://doi. org/10.1556/2006.6.2017.074.

Király, O., Griffiths, M. D., King, D. L., Lee, H.-K., Lee, S.-Y., Bányai, F., Zsila, Á., Takacs, Z. K., \& Demetrovics, Z. (2018). Policy responses to problematic video game use: A systematic review of current measures and future possibilities. Journal of Behavioral Addictions, 7(3), 503517. https://doi.org/10.1556/2006.6.2017.050.

Kowert, R., Domahidi, E., \& Quandt, T. (2014). The relationship between online video game involvement and gaming-related friendships among emotionally sensitive individuals. Cyberpsychology, Behavior and Social Networking, 17(7), 447-453. https://doi.org/ 10.1089/cyber.2013.0656.

Kuo, A., Lutz Richard, J., \& Hiler Jacob, L. (2016). Brave new World of Warcraft: A conceptual framework for active escapism. Journal of Consumer Marketing, 33(7), 498-506. https://doi.org/10.1108/ JCM-04-2016-1775.

Kuss, D. J., Griffiths, M. D., \& Pontes, H. M. (2017). Chaos and confusion in DSM-5 diagnosis of Internet gaming disorder: Issues, concerns, and recommendations for clarity in the field. Journal of Behavioral Addictions, 6(2), 103-109. https://doi.org/10.1556/ 2006.5.2016.062.

Lazarus, R. S. (2006). Emotions and interpersonal relationships: Toward a person-centered conceptualization of emotions and coping. Journal of Personality, 74(1), 9-46. https://doi.org/10.1111/j. 1467-6494.2005.00368.x.

Leonard, D. J. (2019). Virtual anti-racism: Pleasure, catharsis, and hope in Mafia III and Watch Dogs 2. Humanity and Society, 44(1), 111130. https://doi.org/10.1177/0160597619835863.

Meyer, I. H. (2003). Prejudice, social stress, and mental health in lesbian, gay, and bisexual populations: Conceptual issues and research evidence. Psychological Bulletin, 129(5), 674-697. https://doi.org/10. 1037/0033-2909.129.5.674.

Morens, D. M., \& Fauci, A. S. (2020). Emerging pandemic diseases: How we got to COVID-19. Cell., 182, 1077-1092. https://doi.org/ 10.1016/j.cell.2020.08.021.

Nielsen, D. (2015). Identity performance in roleplaying games. Computers and Composition, 38, 45-56. https://doi.org/10.1016/j. compcom.2015.09.003.

Nielsen Community [NielsenKnows]. (2020). [Twitter].

Parcesepe, A. M., \& Cabassa, L. J. (2013). Public stigma of mental illness in the United States: A systematic literature review. Administration and Policy in Mental Health, 40(5), 384-399. https://doi.org/10. 1007/s10488-012-0430-z.

Parker, L. (2016). Video games allow characters more varied sexual identities. The New York Times. https://www.nytimes.com/2016/ 09/01/technology/personaltech/video-games-allow-charactersmore-varied-sexual-orientations.html. Accessed 2 Sept 2020.

Peter, S. C., Li, Q., Pfund, R. A., Whelan, J. P., \& Meyers, A. W. (2019). Public stigma across addictive behaviors: Casino gambling, eSports gambling, and Internet gaming. Journal of Gambling Studies, 35(1), 247-259. https://doi.org/10.1007/s10899-018-9775-x.

Peter, S. C., Ginley, M. K., \& Pfund, R. A. (2020). Assessment and treatment of internet gaming disorder. Journal of Health Service Psychology, 46(1), 29-36. https://doi.org/10.1007/s42843-02000005-2.

Petry, N. M., Zajac, K., \& Ginley, M. K. (2018). Behavioral addictions as mental disorders: To be or not to be? Annual Review of Clinical Psychology, 14, 399-423. https://doi.org/10.1146/annurev-clinpsy032816-045120.
Phillips, G., Felt, D., Ruprecht, M. M., Wang, X., Xu, J., Pérez-Bill, E., Bagnarol, R. M., Roth, J., Curry, C. W., \& Beach, L. B. (2020). Addressing the disproportionate impacts of the COVID-19 pandemic on sexual and gender minority populations in the United States: Actions toward equity. LGBT Health., 7, 279-282. https://doi.org/ 10.1089/lgbt.2020.0187.

Sanchez, T. H., Zlotorzynska, M., Rai, M., \& Baral, S. D. (2020). Characterizing the impact of COVID-19 on men who have sex with men across the United States in April, 2020. AIDS and Behavior, 24(7), 2024-2032. https://doi.org/10.1007/s10461-020-02894-2.

Schneider, L. A., King, D. L., \& Delfabbro, P. H. (2017). Family factors in adolescent problematic Internet gaming: A systematic review. Journal of Behavioral Addictions, 6(3), 321-333. https://doi.org/ 10.1556/2006.6.2017.035.

Sheikh, A., Sheikh, A., Sheikh, Z., \& Dhami, S. (2020). Reopening schools after the COVID-19 lockdown. Journal of Global Health, 10(1), 010376-010376. https://doi.org/10.7189/jogh.10.010376.

Song, J., Park, J. H., Han, D. H., Roh, S., Son, J. H., Choi, T. Y., Lee, H., Kim, T. H., \& Lee, Y. S. (2016). Comparative study of the effects of bupropion and escitalopram on Internet gaming disorder. Psychiatry and Clinical Neurosciences, 70(11), 527-535. https://doi.org/10. $1111 / \mathrm{pcn} .12429$.

The NPD Group (2020). The NPD group: U.S. consumer spend on video game products continues to break records. https://www.npd.com/ wps/portal/npd/us/news/press-releases/2020/the-npd-group-usconsumer-spend-on-video-game-products-continues-to-breakrecords/. Accessed 2 Sept 2020.

van Rooij, A. J., Ferguson, C. J., Colder Carras, M., Kardefelt-Winther, D., Shi, J., Aarseth, E., Bean, A. M., Bergmark, K. H., Brus, A., Coulson, M., Deleuze, J., Dullur, P., Dunkels, E., Edmam, J., Elson, M., Etchells, P. J., Fiskaali, A., Granic, I., et al. (2018). A weak scientific basis for gaming disorder: Let us err on the side of caution. Journal of Behavioral Addictions, 7(1), 1-9. https://doi.org/10. 1556/2006.7.2018.19.

Wang, Q., Ren, H., Long, J., Liu, Y., \& Liu, T. (2019). Research progress and debates on gaming disorder. General Psychiatry, 32(3), e100071-e100071. https://doi.org/10.1136/gpsych-2019-100071.

World Health Organization. (2015). Public health implications of excessive use of the Internet, computers, smartphones and similar electronic devices: Meeting report, Main Meeting Hall, Foundation for Promotion of Cancer Research, National Cancer Research Centre, Tokyo, Japan, 27-29 August 2014. Geneva: World Health Organization.

World Health Organization (2019). World Health Assembly Update, 25 May 2019 [Press release]. https://www.who.int/news-room/detail/ 25-05-2019-world-health-assembly-update. Accessed 2 Sept 2020.

Wu, A. M. S., Chen, J. H., Tong, K.-K., Yu, S., \& Lau, J. T. F. (2018). Prevalence and associated factors of Internet gaming disorder among community dwelling adults in Macao, China. Journal of Behavioral Addictions, 7(1), 62-69. https://doi.org/10.1556/2006. 7.2018.12.

Xiang, Y.-T., Jin, Y., Zhang, L., Li, L., Ungvari, G. S., Ng, C. H., Zhao, M., \& Hao, W. (2020). An overview of the expert consensus on the prevention and treatment of gaming disorder in China (2019 Edition). Neuroscience Bulletin, 36(7), 825-828. https://doi.org/ 10.1007/s12264-020-00475-w.

Zajac, K., Ginley, M. K., Chang, R., \& Petry, N. M. (2017). Treatments for internet gaming disorder and Internet addiction: A systematic review. Psychology of Addictive Behaviors: Journal of the Society of Psychologists in Addictive Behaviors, 31(8), 979-994. https://doi. org/10.1037/adb0000315.

Publisher's Note Springer Nature remains neutral with regard to jurisdictional claims in published maps and institutional affiliations. 